\title{
The emerging role of Cardiovascular Magnetic Resonance in the evaluation of hypertensive heart disease
}

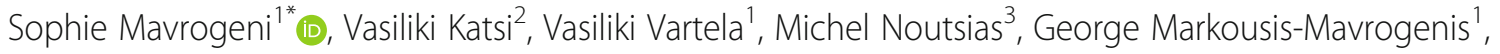
Genovefa Kolovou ${ }^{1}$ and Athanasios Manolis ${ }^{4}$

\begin{abstract}
Background: Arterial hypertension is the commonest cause of cardiovascular death. It may lead to hypertensive heart disease (HHD), including heart failure (HF), ischemic heart disease (IHD) and left ventricular hypertrophy (LVH).

Main body: According to the 2007 ESH/ESC guidelines, the recommended imaging technique is echocardiography (echo), when a more sensitive detection of LVH than that provided by ECG, is needed. Cardiovascular Magnetic Resonance (CMR), a non-invasive, non-radiating technique, offers the following advantages, beyond echo: a) more reliable and reproducible measurements of cardiac parameters such as volumes, ejection fraction and cardiac mass b) more accurate differentiation of LVH etiology by providing information about tissue characterisation c) more accurate evaluation of myocardial ischemia, specifically if small vessels disease is present d) technique of choice for diagnosis of renovascular, aortic tree/branches lesions and quantification of aortic valve regurgitation e) technique of choice for treatment evaluation in clinical trials.

The superiority of CMR against echocardiography in terms of reproducibility, operator independency, unrestricted field of view and capability of tissue characterization makes the technique ideal for evaluation of heart, quantification of aortic valve regurgitation, aorta and aortic branches.

Conclusions: CMR has a great potential in early diagnosis, risk stratification and treatment follow up of HHD. However, an international consensus about CMR in HHD, taking under consideration the cost-benefit ratio, expertise and availability, is still warranted.
\end{abstract}

Keywords: Hypertension, Cardiovascular magnetic resonance, ECG, Echocardiography, Coronary angiography

\section{Background}

Alterations occurring in hypertensive heart disease (HHD) and the role of non-invasive cardiac imaging

Arterial hypertension is the commonest cause of cardiovascular death. It may lead to hypertensive heart disease (HHD) including heart failure (HF), ischemic heart disease (IHD) and left ventricular hypertrophy (LVH). There is no consensus among new HTN practice guidelines as to target treatment of blood pressure (BP) among various subpopulations of patients. However, most guidelines now target a BP $<150 / 90$ for patients $>80 y$, a BP $<140 / 90$ for

\footnotetext{
*Correspondence: soma13@otenet.gr

'Onassis Cardiac Surgery Center, 50 Esperou Street, 17561 P.Faliro, Athens, Greece

Full list of author information is available at the end of the article
}

patients with diabetes or CVD and a BP $<130 / 80$ if diabetes, albuminuria, or high stroke risk is present. In United States, 1 out of every 3 adults has high BP. About $69 \%$ of people with first heart attack, $77 \%$ with first stroke and $74 \%$ with HF have BP higher than 140/90 $\mathrm{mmHg}$ [1].

Essential hypertension accounts for $90 \%$ of adult cases and secondary causes of hypertension for the remaining $10 \%$. According to the Framingham Study, hypertension accounts for about $1 / 4$ of HF cases, and the risk of HF is increased by 2 -fold in men, and 3-fold in women, respectively. Finally, hypertension affects other target organs including kidneys, eyes and peripheral arteries [2].

Left ventricular hypertrophy (LVH) is the response of myocytes to various stimuli leading to myocytes' hypertrophy, which occurs as a compensatory response to 
increased afterload [2]. It is defined as an increase in LV mass, assessed by postmortem measurements, electrocardiographic (ECG), echocardiographic and Cardiovascular Magnetic Resonance (CMR) criteria. Early echocardiographic studies defined LVH as an absolute LV mass (LVM) exceeding $250 \mathrm{~g}$ [2]. Regression of LVH with antihypertensive treatment reduces the risk of stroke, myocardial infarction and all-cause mortality [2]. There are two main patterns of LVH: a) concentric and b) eccentric $\mathrm{LVH}$ [2]. Concentric LVH is considered, when LV mass increases by wall thickening in response to pressure overload, as often in middle aged and elderly patients, is associated with lower cardiac output and predicts poor prognosis. There is a pathway from hypertension to concentric LVH without focal scar [3], hypertension to concentric LVH with focal scar [4], concentric remodelling with myocardial infarction assessed by replacement fibrosis [5], and concentric LVH with symptomatic vascular events and heart failure either with replacement scar [6] or without $[7,8]$. Diastolic dysfunction and/or heart failure with preserved ejection fraction (HFpEF), due to remodelling of the extracellular matrix and increase in LV filling pressures, are common in concentric LVH [9-14]. In eccentric LVH, there is an increase in LV mass without increased concentricity and is associated with higher cardiac output [8] (Fig. 2). It has not been fully clarified why patients develop a specific LVH pattern, as a response to hypertension. Factors such as pressure, volume overload, ethnicity, gender, obesity and plasma renin levels, all seems to play a role [2]; however, the clinical implications of various LVH patterns are still under evaluation. The aim of this review is to discuss the potential advantages and disadvantages of CMR over the currently used echocardiographic techniques and clarify its additive value in the evaluation of HHD.

\section{"Needs and wants" in HHD evaluation}

Various non-invasive techniques have been used to elucidate the pattern of HHD, including HFpEF. ECG and echocardiography were for many years the only techniques for evaluation of HHD. Although ECG measures of LVH were associated with cardiovascular disease risk in the Framingham study [15], the ECG evaluation of LVH lacks sensitivity and specificity, particularly in young male patients $[16,17]$.

Recently, a discrepancy documented in diagnostic performance and agreement on predictive ability suggests that LVH by ECG and LVH by CMR are likely to be two distinct phenotypes [18].

Echocardiography has been successfully used in clinical trials and provided important knowledge in HHD [19]. LVM assessment is useful in severe $\mathrm{LVH}$; however, due to high variability, it underscores patients with mild concentric, eccentric LVH and/or concentric remodelling.
Additionally, a large patients' sample is required to document LVM regression, using M-mode or 2D echocardiography, due to high inter-observer and inter-study variability [20].

CMR, due to its excellent reproducibility, unrestricted field of view and non-invasive, non-radiating tissue characterization, became a powerful player for early diagnosis and treatment assessment of HHD and genderspecific values according to age and body surface area have been already published [21]. The comparison between new echocardiographic techniques and CMR showed that the assessment of LV volumes/LVEF by echocardiography and CMR have good correlations. However, the inter-technique agreement of absolute LV volumes revealed considerable differences, with significant underestimation of volumes and LVEF with respect to CMR [22]. Another study evaluating if LVM by real-time, 3-dimensional echocardiography (RT-3DE) corresponded to CMR in patients with $\mathrm{LVH}$, showed that LVM by RT-3DE correlated with that determined by CMR better than that determined by $2 \mathrm{DE}$, which means that RT-3DE can overcome some of the disadvantages of 2DE in the evaluation of LVM [23]. However, another study, evaluating the accuracy of LVM calculation using new echocardiographic techniques in comparison with CMR in ischemic (IC) and nonischemic cardiomyopathy (non-IC), documented that although more accurate and reliable echocardiographic measurement of LVM was achieved by $3 \mathrm{DE}$, underestimation and variability remained challenges in IC [24]. Finally, a recent study, evaluating 40 patients by echocardiography using 4 imaging modalities (M-mode fundamental imaging [FI], M-mode harmonic imaging [HI], two-dimensional [2D] FI and 2D HI) and CMR, showed that HI overestimates LVM, compared with FI and CMR leading to overestimation of prevalence of $\mathrm{LVH}$ in hypertensive patients. $\mathrm{HI}$ improves inter-observer reproducibility of LVM measurements, compared with FI, leading to a significant decrease in the number of patients required for clinical trials of LVM regression. Finally, the accuracy of LVM measurements by echocardiography is affected by LV geometry [25, 26].

Speckle tracking (ST) alone or combined with tissue Doppler imaging (TDI) seems to be suitable for measurements of regional myocardial deformation and shows better agreement with CMR tagging for regional myocardial strain than measurements based solely on TDI; however, the clinical significance of the detected differences between the methods needs to be further established [27].

\section{CMR "pearls and pitfalls" in the evaluation of HHD}

According to the 2007 ESH/ESC guidelines the recommended imaging technique is echocardiography, when a more sensitive detection of LVH than that provided by ECG is needed, particularly in patients in whom organ damage is not detected by ECG, and in the elderly, in 
whom cardiac hypertrophy is frequent [28]. Additionally, in the 2010 ACCF/ACR/AHA/NASCI/SCMR Expert Consensus Document no recommendation about the usefulness of other techniques, including CMR in the assessment HHD, was discussed [29].

CMR provides a comprehensive non-invasive, nonradiating evaluation of HHD, including accurate and reproducible assessment of biventricular function, valvular disease, inflammation and stress myocardial perfusionfibrosis. Its extensive application has the potential to lead to better understanding of pathophysiology of HHD, promoting more accurate risk stratification and personalised treatment. However, the extensive application of CMR is hampered by serious limitations, such as long examination time, lack of availability and expertise, time consuming post-processing and high cost. As any diagnostic technique, CMR carries various limitations. Scanning patients with metallic clips, pacemakers and other non CMR conditional cardiac devices is not indicated, due to safety reasons. Furthermore, paramagnetic contrast agents can not be used in patients with reduced glomerular filtration rate (GFR) $<30 \mathrm{~mL} / \mathrm{min} / 1.73 \mathrm{~m} 2$, due to risk of nephrogenic systemic fibrosis (NSF) [30], a scleroderma-like disease affecting the skin and internal organs [31]. If GFR is normal, its incidence is less than 1\% [32]; however, in cases with reduced GFR, gadolinium should be given, only if: a) the expected benefits counterbalance the risks, b) using the lowest possible dose and c) avoiding the repeated use.

\section{CMR sequences needed for evaluation of HHD}

Specific sequences for cardiac evaluation include steady state free precession (SSFP) cines for function and wall motion assessment, phase contrast sequences for velocity evaluation, T2-weighted short-tau inversion recovery (STIR) for oedema assessment, T1- and T2-weighted fast spin-echo for tissue characterisation, T1- weighted perfusion and myocardial late gadolinium enhancement (LGE) sequences and 3D-magnetic resonance angiography (MRA). Other more sophisticated CMR techniques such as myocardial tagging, T1, T2 mapping are at the moment part of research in HHD. Currently, 3D-gadolinium enhanced MR angiography (MRA) is considered the imaging technique of choice for evaluation of renovascular hypertension and MRI is also excellent to localize tumours leading to pheochromocytoma and primary aldosteronism. However, at the moment, no specific indications for CMR in HHD have been proposed [33].

\section{Comparison with other imaging techniques}

The main imaging technique for comparison with CMR remains echocardiography, since both computed tomography $(\mathrm{CT})$ and nuclear techniques are not included in the routine evaluation of HHD and are used only if there are specific indications. Compared with these techniques CMR has the following advantages:

\section{High reproducibility of measurements}

CMR is more reproducible than both $\mathrm{M}$ mode and 2D echocardiography for the estimation of LVM, because it does not require geometric assumptions, according to data validated by animal studies [24-36]. It provides an excellent contrast between blood and myocardium and has high spatial resolution, leading to accurate definition of endocardial and epicardial contours. Steady-state free precession (SSFP) cine imaging is the sequence of choice for measuring LVM by CMR. Usually, the absolute values of LVM by CMR are lower compared with echocardiography, because a) SSFP allows the visualization and inclusion of myocardial trabeculations in the LV volume with simultaneous exclusion from mass calculation b) the echocardiographic evaluation is based on geometric assumptions that is not the case for CMR

\section{Easier and faster evaluation of treatment}

CMR or 3D echocardiography are the techniques of choice in trials evaluating LVM regression, because they allow the accurate detection of small changes of LVM in small patients' cohorts, particularly when recruitment of large patients' numbers is not feasible. CMR, due to its high reproducibility, can demonstrate reduction in LVM and volumes with normalization of LVEF after a short period of better blood pressure (BP) control using appropriate medication $[37,38]$ and has been used to assess LVM regression after treatment of HHD in various studies including:

a) the LIFE substudy in which the effect of high BP to ventricular remodelling was assessed [39]

b) the TELMAR study [40], which compared the effect of telmisartan to metoprolol on LVH in uncontrolled hypertension

c) the LVH-4E [41], in which eplerenone was compared to enalapril or a combination of both in LVH regression in hypertensive patients

d) the ALIVE study [39], in which benazepril with either amlodipine or a diuretic was evaluated and recently

e) the ALLAY trial [42], in which aliskiren, a direct renin inhibitor, was proved to be as effective as losartan for reduction of LVM.

\section{Evaluation of intramyocardial function}

CMR tissue tagging allowed the non-invasive assessment of intramyocardial displacement / strain by monitoring motion of specific material points spread in the myocardium [43-47]. The application of this technique in large epidemiologic studies such as the Multi-Ethnic Study of Atherosclerosis (MESA) [48] has enabled to investigate 
the nature of atherosclerosis in a total of 1184 asymptomatic participants (aged 45-84 years). Regional LV function was quantified by evaluating peak systolic circumferential strain (Ecc). The study proved that higher diastolic blood pressure (DBP) was associated with decreased regional LV function in asymptomatic individuals [49] and was significantly attenuated after controlling for LVM. Furthermore, LV torsional deformation was greater in hypertensive patients, despite that they had lower circumferential shortening, because torsion in hypertension with concentric remodeling is a compensatory mechanism to maintain LVEF [49].

In contrast, the echocardiographic evaluation of LV deformation is a geometry-based index, derived from linear measurements of the posterior and the septal wall and cannot distinguish between septal and posterior wall function. Thus, it is unknown, whether depressed LV deformation represents global or regional intrinsic depression of LV myocardial function in hypertrophy, due to pressure-overload [50]. In addition, the assessment of torsional deformation by echocardiography is methodologically challenging, because the distance between the basal and the apical short-axis slices can not be accurately assessed by this technique [50].

\section{Diastolic dysfunction}

Diastolic dysfunction is the earliest expression of HHD [51, 52], affects approximately $50 \%$ of hypertensive patients worldwide [52], correlates with the degree of LVH $[53,54]$ and is remarkably improved in cases with LVH regression (54). Currently, the most widely applied technique to assess LV diastolic function is the evaluation of transmitral inflow or pulmonary venous flows using Doppler echocardiography [55-58]. However, echocardiography measures the impact of altered LV diastolic properties by evaluating diastolic flow velocities, due to pressure gradient changes at the mitral orifice and flow velocities in the pulmonary veins and is unable to evaluate LV relaxation directly. Furthermore, the conventional Doppler measurements are very much load-dependent and can change dramatically during minimal alterations in heart rate and/or ventricular preload [58]. This defect can be overcome by the application of Tissue Doppler Imaging (TDI), which measures early diastolic mitral annular velocity (Ea) and late, due to atrial contraction, diastolic mitral annular velocity (Am) [59]. Ea of the lateral basal part of LV does not change significantly and any consequence, due to preload change, can be corrected by a ratio of $\mathrm{E} / \mathrm{Ea}$ [59]. Additionally, 2D-speckle imaging provides a direct angle- and geometry-independent measure of circumferential strain $(\varepsilon)[60,61]$.

There is an excellent agreement between CMR and transthoracic echocardio-graphy for the assessment of diastolic inflow [62]. CMR has the potential to evaluate the diastolic function during both active and passive stages with the additive value of assessment of myocardial velocities [63], providing insights unavailable by other non-invasive imaging techniques. Recently, a novel CMRderived index -diastolic volume recovery, calculated as the percentage proportion of diastole required for recovery of $80 \%$ stroke volume, has been shown to give the best result, compared with echocardiography for the detection of diastolic dysfunction [64]. Additionally, atrial size is an independent factor associated with CV morbidity and mortality [65] and the possibility of atrial fibrillation [66]. Assessment of atrial volumes by echocardio-graphy is inaccurate, due to geometric assumptions about their shape [67]. In contrary, CMR offers an accurate and reproducible measurement of atrial volumes and recently reference values of left atrial volume by CMR became available [68]. However, until now, due to high availability and temporal resolution of echocardiography, CMR has not been used as a routine tool for diastolic function evaluation.

\section{Differentiation of various causes of $\mathrm{LVH}$}

The differentiation of aetiology of $\mathrm{LVH}$ is intriguing, because various forms of LVH may present with overlapping phenotypes. Various myocardial abnormalities including infiltrative diseases, hypertrophic cardiomyopathy (HCM), Fabry's disease, cardiac sarcoidosis, aortic stenosis and athlete's heart can be presented with LVH.

CMR is superior to echocardiography for HCM diagnosis, by identifying areas of segmental hypertrophy (ie, anterolateral wall or apex) not reliably visualized by echocardiography (or underestimated in extent). Highrisk HCM subgroups, identified with CMR, include those with thin-walled scarred LV apical aneurysms (which prior to CMR imaging remained usually undetected), end-stage systolic dysfunction and massive LV hypertrophy. CMR observations also suggest that the cardiomyopathic process in HCM is more diffuse than previously observed, extending beyond the LV myocardium to include thickening of the right ventricular wall as well as substantial morphologic diversity with regard to papillary muscles and mitral valve. These findings have implications for management in HCM undergoing invasive septal reduction therapy. Among HCM families, CMR has identified unique phenotypes of affected genetic status in the absence of LV hypertrophy, including myocardial crypts, elongated mitral valve leaflets and late gadolinium enhancement [69]. CMR may also raise suspicion of various infiltrative cardiomyopathies, such as cardiac amyloidosis, glyocogen/lysosomal storage diseases including Fabry's, Danons, and AMP kinase diseases. The demonstration of nearly identically increased wall thickness in both the septum and LV free wall, by cine CMR, combined with diffuse subendocardial LGE is highly specific for cardiac amyloidosis. A similar pattern of concentric wall thickening 
with LGE confined to the basal inferolateral wall has been frequently reported in Fabry's disease. CMR may suggest the aetiology of LVH; however, confirmatory diagnosis requires the identification of a disease-causing mutation by genetic testing or typical histopathology on cardiac biopsy [69].

CMR can be also helpful in detecting changes in serial measurements of LV wall thickness after treatment with antihypertensives, in which regression of hypertrophy supports the diagnosis of hypertensive cardiomyopathy. In hypertensive patients, CMR documented reduced ejection fraction/anteroseptal systolic strains and increased cardiac chamber volumes/LV wall stress, while in HCM, revealed supernormal ejection fraction, reduced LV wall stress/longitudinal systolic strain and fibrosis. Increased LV wall stress was the hallmark of hypertension, while HCM was characterized by reduced total longitudinal strain. Finally, athlete's heart was distinguished from other types of hypertrophy by using the CMR-derived diastolic wall-to-volume ratio [70]. Although it needs further validation, a cut-off value of less than $0.15 \mathrm{~mm} \times \mathrm{m} 2 / \mathrm{ml}$ has $99 \%$ specificity for sport-related LVH [70].

To conclude, although ECG has high specificity for the detection of $\mathrm{LVH}$, it is unable to identify the type of hypertrophy. This is because the ECG thresholds are generally selected to optimize specificity. Finally, standard ECG criteria for LVH have low sensitivity for CMR $\mathrm{LVH}$, and few false positives and more false negatives.Echocardiography, although widely available and cost effective, carries the significant disadvantages of operator and acoustic window dependency and restricted field of view. In contrary, the CMR capability to offer detailed and highly reproducible wall motion evaluation without assumptions and concurrent tissue characterisation can significantly facilitate the differential diagnosis of various diseases presented with $\mathrm{LVH}$.

\section{Fibrosis assessment}

Myocardial fibrosis is the common end point of various pathologic processes in HHD and plays an important role in the development of diastolic dysfunction [71, 72]. The most robust approach to quantify replacement myocardial fibrosis is late gadolinium enhancement (LGE) [73]; it represents gadolinium enhancement in regions of fibrosis using T1-weighted images, taken 10-15 min after intravenous administration of gadolinium-based contrast agent. The pathophysiologic mechanism behind LGE includes a) expansion of extravascular volume in fibrotic myocardium, occupied by the extracellular distribution of contrast agent b) impaired kinetics of gadolinium due to vascular changes in fibrotic myocardium. Patchy LGE has been documented in approximately $50 \%$ of patients with LVH due to arterial hypertension [74], and was clearly distinguishable from the subendocardial LGE
(Fig. 4), due to myocardial infarction. LGE can be also found in hypertrophic cardiomyopathy, and its quantification can differentiate those patients in high risk for sudden cardiac death [75] (Figs. 1, 2, 3 and 4).

Recent studies proved that the severity of diastolic dysfunction increases in parallel with the extent of fibrosis, assessed by LGE [76]. However, discrete LGE areas may be absent in HHD. Unfortunately, diffuse myocardial fibrosis can not be detected by LGE, because LGE relies on the signal intensity differences between fibrotic and normal myocardium and this is a serious drawback of the technique. This phenomenon has motivated the development of the technique of T1 mapping by which quantification of diffuse myocardial fibrosis can be achieved; T1 mapping represents an independent discriminator between HCM and hypertension, over and above extracellular volume fraction (ECV), LV wall thickness and indexed LVM [77]. There are data demonstrating significant differences in myocardial contrast accumulation between controls and HF patients using post-contrast T1 mapping with concurrent histologic data supporting that these changes reflect diffuse fibrosis. T1 mapping has the potential to be the end point in future trials, assessing antifibrotic treatment in HHD, without using serial endomyocardial tissue biopsies $[4,78,79]$.

Finally, in well-controlled hypertensive patients, conventional CMR discovered significant underlying diseases (infarction, HCM), undetected by echocardiography. In these patients, T1 mapping revealed increased diffuse myocardial fibrosis, but this increase was small and only occurred with LVH [80]. However, in another study T1 mapping was an independent discriminator between HCM and hypertension, over and above extracellular volume fraction (ECV), LV wall thickness and LVM [81].

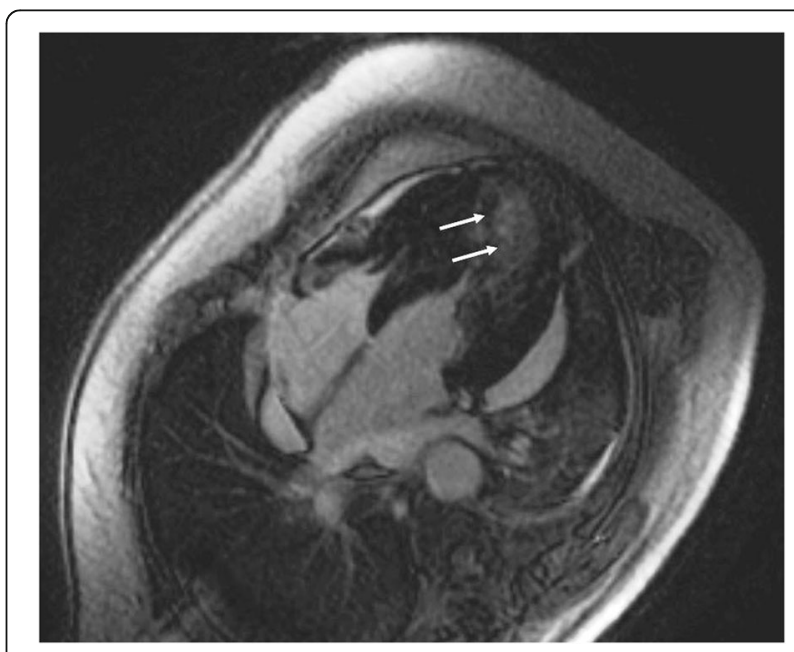

Fig. 1 Four chamber LGE in a patient with extensive hypertrophy due to HCM. There are clear fibrotic areas in the interventricular septum, lateral wall of LV and apex, providing diagnostic and prognostic information about future cardiac events 


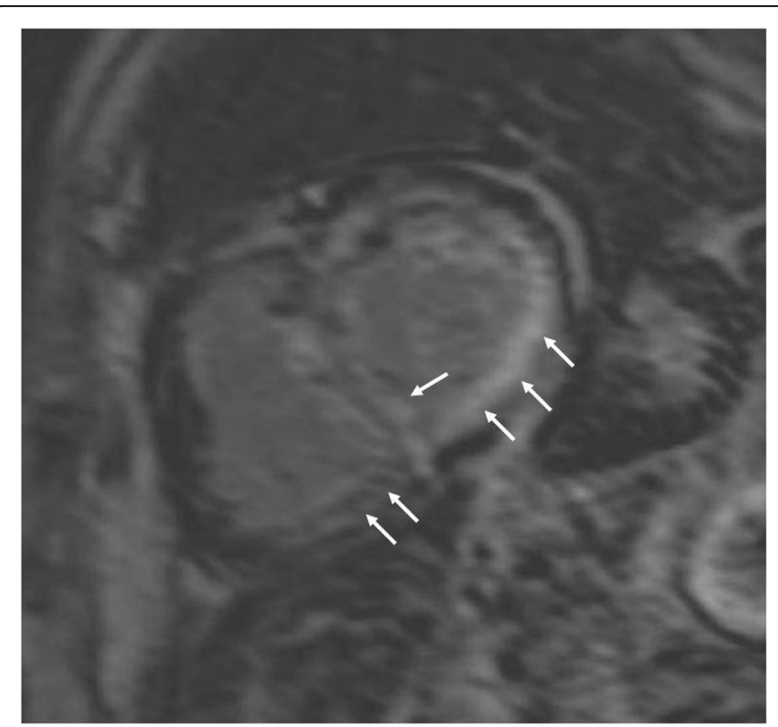

Fig. 2 Short axis LGE in a patient with with amyloidosis. Evidence of amyloid depositions in both ventricles (arrows)

Although tissue biopsy is the gold standard for diagnosis of myocardial fibrosis, some circulating biomarkers have been also proposed for the non-invasive assessment of fibrosis. It was suggested that galectin-3 (Gal-3) is associated with myocardial histological and molecular parameters related to fibrosis and with the circulating biomarkers of the extracellular generation of mature fibril-forming collagen types I (C-terminal propeptide of procollagen type I, PICP) and III (N-terminal propeptide of procollagen type III, PIIINP) in two independent studies of hypertensive patients with heart failure (HF). However, data from various studies are rather contradictory. The excess of cardiac and systemic Gal-3 in HF patients of hypertensive origin was not associated with

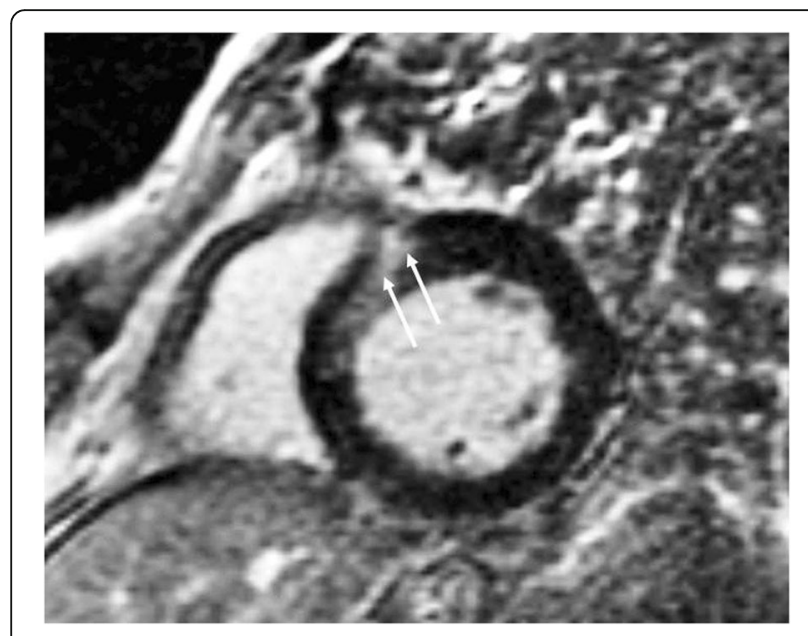

Fig. 3 Short axis LGE in a patient with HHD and evidence of intranyocardial fibrosis in the interventricular septum

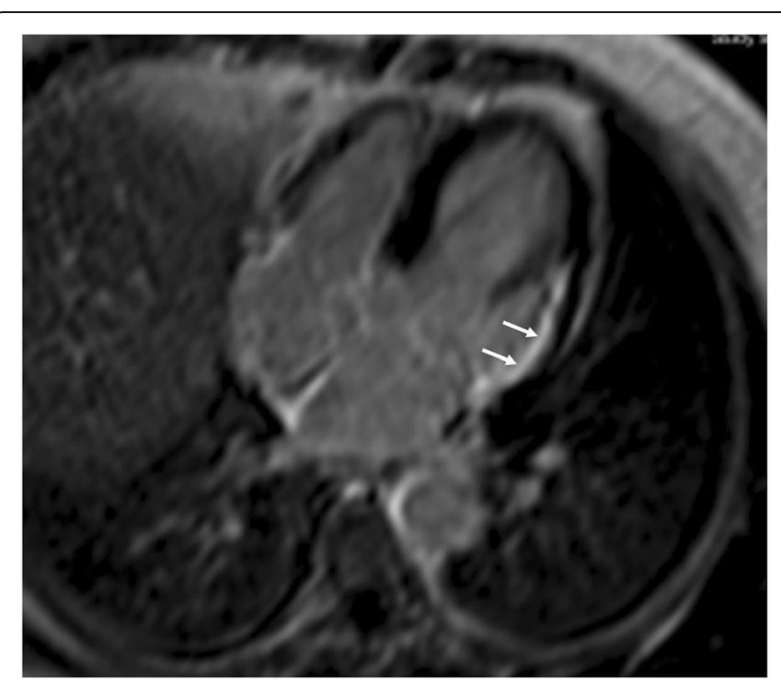

Fig. 4 Subendocardial LGE in the lateral wall of LV, due to myocardial infarction in a patient with coronary artery disease

histological, molecular and/or biochemical parameters related to myocardial fibrosis in these patients [82]. Furthermore, a review of the literature about biomarkers showed that most of them lack proof for representing true myocardial fibrosis [83]. However, in another study, elevated serum levels of Gal-3 were in agreement with the degree of myocardial fibrosis assessed by LGE [84].

\section{Ischemia detection}

In HHD, coronary circulation changes take place, independently of occlusive atherosclerotic disease of epicardial coronary arteries. Furthermore, abnormalities in the coronary microcirculation, which accompany cardiac hypertrophy, play an important role in the pathophysiology of complications, attributed to LVH [85]. Although in clinical practice, the ECG is the first test to assess LVH [86, 87], false positives results are very common. Furthermore, a normal ECG can not exclude LVH [88]. Myocardial perfusion scintigraphy can potentially have a place in the detection of reduced coronary flow reserve in HHD. However, there are several technical issues with this technique in HHD, because any myocardial pathology, frequently assessed in these patients, can lead to abnormal images. Patients with HHD and concurrent LVH may have perfusion defects, unrelated to coronary artery disease (CAD). Their images can be false interpreted as evidence of myocardial ischemia, due to CAD $[89,90]$. Furthermore, in HHD with LVH and/or microvascular disease, myocardial perfusion abnormalities were frequently documented in hypertensive patients with associated angiographically normal epicardial coronary arteries [90]. Stress echocardiography has a better 
specificity for detection of angiographically documented CAD [91]; however, the sensitivity of wall motion abnormalities for ischemia detection was significantly reduced, when LVH coexisted.

Stress perfusion CMR permits the non-invasive differentiation between hemodynamically significant coronary artery stenosis and microvascular disease, due to hypertension and/or diabetes, based on high temporal and spatial resolution of the technique. In small vessel disease, the perfusion defects are usually diffuse, circumferential, affecting $\leq 1 / 3$ of the wall thickness and have shorter persistence ( $\leq 5$ heartbeats) compared with those in patients with significant epicardial coronary disease (Fig. 5) [92-95]. This differentiation is important for both treatment and prognosis [96, 97]. CMR can also identify coronary flow abnormalities in HHD with normal coronary arteries $[98,99]$. Additionally, more than half of the scar detected by CMR-LGE was undetected by ECG $[5,6]$.

\section{CMR indications in HHD}

Clinical evaluation, ECG and echocardiography constitute the cornerstones for both diagnosis and follow up of HHD and remain the absolutely necessary examinations for HHD patients. However, a CMR evaluation is indicated if there is a) an inconclusive echocardiogram, b) a mismatch between clinical evaluation, ECG and echocardiography and c) severe, rapidly progressive LVH. Finally, due to high reproducibility, it is the ideal tool for clinical trials. In more details, the CMR indications in HHD are presented in Table 1.

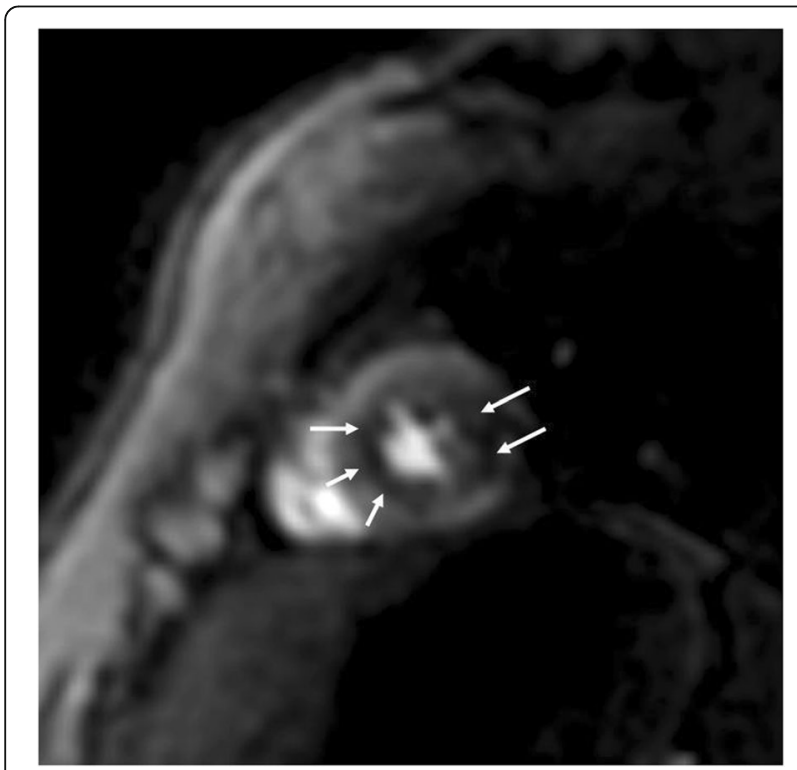

Fig. 5 Diffuse subendocardial perfusion defect, detected by adenosine stress perfusion CMR, in a patient with $\mathrm{HHD}$
Table 1 Potential CMR indications in hypertensive heart disease Aggressive, rapidly progressive hypertension

Poor acoustic window

HHD and stroke (to exclude the potential of aortic plaques)

Differential diagnosis of the etiology of LV hypertrophy

Quantification of concurrent aortic valve regurgitation

Evaluation of aortic tree anatomy and exclusion of potential renovascular disease

Differential diagnosis of the etiology and pattern of fibrosis

Documentation of microvascular cardiac disease

Evaluation of treatment

Reduction of the clinical studies cost (smaller patients' sample for drug validation is needed by CMR)

\section{Conclusions}

HHD is the commonest cause of cardiovascular death with detrimental impact on patients' morbidity and mortality and also health care costs. Although detailed guidelines determining the clinical indications of CMR in hypertension are still missing, CMR can provide early and highly reproducible evaluation of LVH and remodelling, not available by any other non-invasive technique; furthermore, the capability to perform tissue characterisation facilitates the early diagnosis and better risk stratification of micro-, macro-vascular ischemia and fibrosis, commonly found in hypertensive patients, with potentially high impact on their treatment and also on health care costs.

\section{Key points}

1. Hypertensive heart disease (HHD) includes
a) Left ventricular hypertrophy (LVH),
b) congestive heart failure (CHF),
c) ischemic heart disease (IHD)

2. ECG evaluation of LVH lacks sensitivity and specificity, particularly in young male patients

3. 2D Echocardiographic assessment of LV mass (LVM) is useful in patients with severe LVH; however, it has high interobserver/interstudy variability

4. LV mass assessed by RT-3DE correlates with CMR better than that determined by $2 \mathrm{DE}$; however, underestimation and variability remain challenges in patients with ischemic cardiomyopathy

5. CMR offers:
a) High reproducibility of measurements
b) Easier and faster evaluation of treatment
c) Evaluation of intramyocardial function
d) Evaluation of Diastolic dysfunction
e) Differentiation of various causes of LVH
f) Fibrosis assessment
g) Ischemia detection 


\section{Abbreviations}

2D E: 2 Dimentional Echocardiography; Am: Atrial contraction, diastolic mitral annular velocity; CAD: Coronary artery disease; CHF: Congestive heart failure; CMR: Cardiovascular Magnetic Resonance; Ea: Early diastolic mitral annular velocity; ECG: Electrocardiogram; EF: Ejection fraction; FI: M-mode fundamental imaging; Gal-3: Galectin 3; HCM: Hypertrophic Cardiomyopathy; HF: Heart failure; HFpEF: Heart failure with preserved ejection fraction; HHD: Hypertensive heart disease; HI: M-mode harmonic imaging; IHD: Ischemic heart disease; IHD: Ischemic heart disease; IVS: Intra-ventricular septal; LGE: Late gadolinium enhancement; LV: Left ventricle; LVH: Left ventricular hypertrophy; LVM: Left ventricular mass; NSF: Nephrogenic fibrosis syndrome; PICP: C-terminal propeptide of procollagen type I; PIIINP: Nterminal propeptide of procollagen type III; RT-3DE: 3 Dimentional Echocardiography; RV: Right ventricle; SSFP: Steady-state free precession; STIR: T2 T2-weighted short-tau inversion recovery

\section{Acknowledgements}

Not applicable.

\section{Funding}

Not applicable.

\section{Availability of data and materials}

Not applicable.

\section{Authors' contributions}

SM, responsible for the overall project management, data gathering and co-ordination. Co-authored most sections in the manuscript. VK, W, responsible for authoring sections regarding echocardiography. MN, GMM, responsible for proofreading, additional suggestions and correction of reviewer comments. GK, AM, team co-ordination, Image collection and processing. All authors read and approved the final manuscript.

\section{Competing interests}

Sophie Mavrogeni and Michael Noutsias declare that they serve on the editorial board of BMC Cardiovascular Disorders. Michel Noutsias has been consultant to the IKDT (Institute for Cardiac Diagnosis and Therapy GmbH, Berlin) 2004-2008, and has received honoraria for presentations and/or participated in advisory boards from AstraZeneca, Bayer, Fresenius, Miltenyi Biotech, Novartis, Pfizer and Zoll. Other authors declare that they have no competing interests.

\section{Consent for publication}

Not applicable.

\section{Ethics approval and consent to participate}

Not applicable.

\section{Publisher's Note}

Springer Nature remains neutral with regard to jurisdictional claims in published maps and institutional affiliations.

\section{Author details}

'Onassis Cardiac Surgery Center, 50 Esperou Street, 17561 P.Faliro, Athens, Greece. ${ }^{2}$ Hippokration Hospital, Athens, Greece. ${ }^{3}$ Department of Cardiology, Pneumonology and Intensive Care Medicine, Clinic for Internal Medicine I, University Hospital Jena, Friedrich-Schiller-University, Jena, Germany. ${ }^{4}$ Asklipiion Voulas, Athens, Greece.

Received: 5 March 2017 Accepted: 7 May 2017

Published online: 23 May 2017

\section{References}

1. Go AS, Mozaffarian D, Roger VL, Benjamin EJ, Berry JD, Borden WB, Bravata DM, Dai S, Ford ES, Fox CS, Franco S, Fullerton HJ, Gillespie C, Hailpern SM, Heit JA, Howard VJ, Huffman MD, Kissela BM, Kittner SJ, Lackland DT, Lichtman JH, Lisabeth LD, Magid D, Marcus GM, Marelli A, Matchar DB, DK MG, Mohler ER, Moy CS, Mussolino ME, Nichol G, Paynter NP, Schreiner PJ, Sorlie PD, Stein J, Turan TN, Virani SS, Wong ND, Woo D, Turner MB, on behalf of the American Heart Association Statistics Committee and Stroke Statistics Subcommittee. Heart disease and stroke statistics—2013 update: a report from the American Heart Association. Circulation. 2013;127:e6-e245.
2. Drazner MH. The progression of hypertensive heart disease. Circulation. 2011;123(3):327-34.

3. Yoneyama K, Gjesdal O, Choi EY, et al. Age, sex, and hypertension-related remodeling influences left ventricular torsion assessed by tagged cardiac magnetic resonance in asymptomatic individuals: the multi-ethnic study of atherosclerosis. Circulation. 2012;126:2481-90.

4. Ambale Venkatesh B, Volpe GJ, Donekal S, et al. Association of longitudinal changes in left ventricular structure and function with myocardial fibrosis: the multi-ethnic study of atherosclerosis study. Hypertension. 2014;64:508-15.

5. Turkbey EB, Nacif MS, Guo M, et al. Prevalence and correlates of myocardial scar in a US cohort. JAMA. 2015;314:1945-54.

6. Schelbert EB, Cao JJ, Sigurdsson S, et al. Prevalence and prognosis of unrecognized myocardial infarction determined by cardiac magnetic resonance in older adults. JAMA. 2012;308:890-6.

7. Bluemke DA, Kronmal RA, Lima JA, et al. The relationship of left ventricular mass and geometry to incident cardiovascular events: the MESA (multiethnic study of atherosclerosis) study. J Am Coll Cardiol. 2008;52:2148-55.

8. Chahal $\mathrm{H}$, Bluemke DA, Wu CO, et al. Heart failure risk prediction in the multi-ethnic study of atherosclerosis. Heart. 2015;101:58-64.

9. Levy D, Garrison RJ, Savage DD, Kannel WB, Castelli WP. Prognostic implications of echocardiographically determined left ventricular mass in the Framingham heart study. N Engl J Med. 1990;322(22):1561-6.

10. Berk BC, Fujiwara K, Lehoux S. ECM remodelling in hypertensive heart disease. J Clin Invest. 2007;117(3):568-75.

11. Liu CY, Liu YC, Wu C, et al. Evaluation of age-related interstitial myocardial fibrosis with cardiac magnetic resonance contrast-enhanced T1 mapping: MESA (multi-ethnic study of atherosclerosis). J Am Coll Cardiol. 2013;62:1280-7.

12. Houghton JL, Frank MJ, Carr AA, von Dohlen TW, Prisant LM. Relations among impaired coronary flow reserve, left ventricular hypertrophy and thallium perfusion defects in hypertensive patients without obstructive coronary artery disease. J Am Coll Cardiol. 1990;15:43-51.

13. Davies JE, Whinnett ZI, Francis DP, et al. Evidence of a dominant backwardpropagating "suction" wave responsible for diastolic coronary filling in humans, attenuated in left ventricular hypertrophy. Circulation. 2006;113:1768-78.

14. Devereux RB, Reichek N. Echocardiographic determination of left ventricular mass in man. Anatomic validation of the method. Circulation. 1977;55(4):613-8.

15. Kannel WB, Gordon T, Offutt D. Left ventricular hypertrophy by electrocardiogram. Prevalence, incidence, and mortality in the Framingham study. Ann Intern Med. 1969;71(1):89-105.

16. Pewsner $D$, Jüni $P$, Egger $M$, Battaglia $M$, Sundström J, Bachmann LM. Accuracy of electrocardiography in diagnosis of left ventricular hypertrophy in arterial hypertension: systematic review. BMJ. 2007;335(7622):711.

17. Bratincsák A, Williams M, Kimata C, Perry JC. The electrocardiogram is a poor diagnostic tool to detect left ventricular hypertrophy in children: a comparison with Echocardiographic assessment of left ventricular Mass Congenit Heart Dis 2015; 10(4):E164-E171.

18. Bacharova L, Chen H, Estes EH, Mateasik A, Bluemke DA, Lima JA, Burke GL, Soliman EZ. Determinants of discrepancies in detection and comparison of the prognostic significance of left ventricular hypertrophy by electrocardiogram and cardiac magnetic resonance imaging. Am J Cardiol. 2015;115(4):515-22.

19. Devereux RB, Dahlof B, Gerdts E, et al. Regression of hypertensive left ventricular hypertrophy by losartan compared with atenolol: the Losartan Intervention for Endpoint reduction in Hypertension (LIFE) trial. Circulation. 2004;110:1456-62.

20. Grothues F, Smith GC, Moon JC, et al. Comparison of interstudy reproducibility of cardiovascular magnetic resonance with two-dimensional echocardiography in normal subjects and in patients with heart failure or left ventricular hypertrophy. Am J Cardiol. 2002;90(1):29-34.

21. Alfakih K, Walters K, Jones T, Ridgway J, Hall AS, Sivananthan M. New genderspecific partition values for ECG criteria of left ventricular hypertrophy: recalibration against cardiac MRI. Hypertension. 2004;44(2):175-9.

22. Aurich M, André F, Keller M, Greiner S, Hess A, Buss SJ, Katus HA, Mereles D. Assessment of left ventricular volumes with echocardiography and cardiac magnetic resonance imaging: real-life evaluation of standard versus new semiautomatic methods. J Am Soc Echocardiogr. 2014;27(10):1017-24.

23. Oe H, Hozumi T, Arai K, Matsumura Y, Negishi K, Sugioka K, Ujino K, Takemoto $Y$, Inoue $Y$, Yoshikawa J. Comparison of accurate measurement of left ventricular mass in patients with hypertrophied hearts by real-time three-dimensional echocardio-graphy versus magnetic resonance imaging Am J Cardiol. 2005;95(10):1263-7.

24. Kusunose K, Kwon DH, Motoki H, Flamm SD, Marwick TH. Comparison of threedimensional echocardiographic findings to those of magnetic resonance 
imaging for determination of left ventricular mass in patients with ischemic and non-ischemic cardiomyopathy. Am J Cardiol. 2013;112(4):604-11.

25. Perdrix L, Mansencal N, Cocheteux B, Chatellier G, Bissery A, Diebold B, Mousseaux $E$, Abergel $E$. How to calculate left ventricular mass in routine practice? An echocardiographic versus cardiac magnetic resonance study. Arch Cardiovasc Dis. 2011;104(5):343-51.

26. Park JH, Negishi K, Kwon DH, Popovic ZB, Grimm RA, Marwick TH. Validation of global longitudinal strain and strain rate as reliable markers of right ventricular dysfunction: comparison with cardiac magnetic resonance and outcome. J Cardiovasc Ultrasound. 2014;22(3):113-20.

27. Amundsen BH, Crosby J, Steen PA, Torp H, Slørdahl SA, Støylen A. Regional myocardial long-axis strain and strain rate measured by different tissue Doppler and speckle tracking echocardiography methods: a comparison with tagged magnetic resonance imaging. Eur J Echocardiogr. 2009;10(2):229-37.

28. The Task Force for the Management of Arterial Hypertension of the European Society of Hypertension (ESH) and of the European Society of Cardiology (ESC). Guidelines for the management of arterial Hypertensión. Eur Heart J. 2007;28:1462-536.

29. American College of Cardiology Foundation Task Force on Expert Consensus Documents, Hundley WG, Bluemke DA, Finn JP, Flamm SD, Fogel MA, Friedrich MG, Ho VB, Jerosch-Herold M, Kramer CM, Manning WJ, Patel M, Pohost GM, Stillman AE, White RD, Woodard PK. ACCF/ACR/AHA/ NASCI/SCMR 2010 expert consensus document on cardiovascular magnetic resonance: a report of the American College of Cardiology Foundation Task Force on expert consensus documents. J Am Coll Cardiol. 2010;55:2614-62.

30. Varghese A, Crowe LA, Mohiaddin RH, Gatehouse PD, Yang GZ, Firmin DN, et al. Inter-study reproducibility of 3D volume selective fast spin echo sequence for quantifying carotid artery wall volume in asymptomatic subjects. Atherosclerosis. 2005;183:361-6.

31. Sadowski EA, Bennett LK, Chan MR, Wentland AL, Al G, Garrett RW, Djamali A. Nephrogenic systemic fibrosis: risk factors and incidence estimation. Radiology. 2007;243:148-57.

32. Reiter T, Ritter $O$, Prince MR, Nordbeck P, Wanner C, Nagel E, Bauer WR. Minimizing risk of nephrogenic systemic fibrosis in cardiovascular magnetic resonance. J Cardiovasc Magn Reson. 2012;14:31.

33. Maceira and Mohiaddin. Cardiovascular magnetic resonance in systemic hypertension J Cardiovasc Magn Reson 2012; 14:28.

34. Katz J, Milliken MC, Stray-Gundersen J, et al. Estimation of human myocardial mass with MR imaging. Radiology. 1988;169(2):495-8.

35. Florentine MS, Grosskreutz CL, Chang W, et al. Measurement of left ventricular mass in vivo using gated nuclear magnetic resonance imaging. J Am Coll Cardiol. 1986:8(1):107-12.

36. Keller AM, Peshock RM, Malloy CR, et al. In vivo measurement of myocardial mass using nuclear magnetic resonance imaging. J Am Coll Cardiol. 1986:8(1):113-7.

37. Reichek N, Devereux RB, Rocha RA, et al. Magnetic resonance imaging left ventricular mass reduction with fixed-dose angiotensin-converting enzyme inhibitor-based regimens in patients with high-risk hypertension. Hypertension. 2009;54(4):731-7

38. Pitt B, Reichek N, Willenbrock R, et al. Effects of eplerenone, enalapril, and eplerenone/enalapril in patients with essential hypertension and left ventricular hypertrophy: the 4E-left ventricular hypertrophy study. Circulation. 2003;108(15):1831-8.

39. Olsen MH, Wachtell $\mathrm{K}$, Hermann $\mathrm{KL}$, Frandsen $\mathrm{E}$, Dige-Petersen $\mathrm{H}$, Rokkedal J, Devereux $\mathrm{R}$, Ibsen $\mathrm{H}$. Is cardiovascular remodeling in patients with essential hypertension related to more than high blood pressure? A LIFE substudy. Losartan Intervention for Endpoint-reduction in Hypertension. Am Heart J. 2002;144:530-7.

40. Friedrich MG, Dahlof B, Sechtem U, Unger T, Knecht M, Dietz R. TELMAR investigators. Reduction (TELMAR) as assessed by magnetic resonance imaging in patients with mild-to-moderate hypertension-a prospective, randomised, double-blind comparison of telmisartan with metoprolol over a period of 6 months rationale and study design. J Renin-AngiotensinAldosterone Syst. 2003;4:234-43.

41. Williams GH, Burgess E, Kolloch RE, Ruilope LM, Niegowska J, Kipnes MS, Roniker B, Patrick JL, Krause SL. Efficacy of eplerenone versus enalapril as monotherapy in systemic hypertension. Am J Cardiol. 2004 Apr 15;93(8):990-6.

42. Solomon SD, Appelbaum E, Manning WJ, Verma A, Berglund T, Lukashevich V, Cherif Papst C, Smith BA, Dahlöf B. Aliskiren in left ventricular hypertrophy (ALLAY) trial investigators. Effect of the direct Renin inhibitor aliskiren, the Angiotensin receptor blocker losartan, or both on left ventricular mass in patients with hypertension and left ventricular hypertrophy. Circulation. 2009;119:530-7.
43. Axel L, Dougherty L. MR imaging of motion with spatial modulation of magnetization. Radiology. 1989;171(3):841-5.

44. Young AA, Imai H, Chang CN, Axel L. Two-dimensional left ventricular deformation during systole using magnetic resonance imaging with spatial modulation of magnetization. Circulation. 1994;89(2):740-52.

45. Clark NR, Reichek N, Bergey P, et al. Circumferential myocardial shortening in the normal human left ventricle. Assessment by magnetic resonance imaging using spatial modulation of magnetization. Circulation. 1991;84(1):67-74.

46. Palmon LC, Reichek N, Yeon SB, et al. Intramural myocardial shortening in hypertensive left ventricular hypertrophy with normal pump function. Circulation. 1994;89(1):122-31.

47. Osman NF, Prince JL. Visualizing myocardial function using HARP MRI. Phys Med Biol. 2000;45(6):1665-82.

48. Rosen BD, Saad MF, Shea S, et al. Hypertension and smoking are associated with reduced regional left ventricular function in asymptomatic: individuals the multi-ethnic study of atherosclerosis. JAm Coll Cardiol. 2006;47(6):1150-8.

49. Gaasch WH, Zile MR. Left ventricular diastolic dysfunction and diastolic heart failure. Annu Rev Med. 2004;55:373-94.

50. Tadic M, Cuspidi C, Majstorovic A, Kocijancic V, Celic V. The relationship between left ventricular deformation and different geometric patterns according to the updated classification: findings from the hypertensive population J Hypertens 2015; 33(9):1954-1961.

51. Redfield MM, Jacobsen SJ, Burnett JC Jr, Mahoney DW, Bailey KR, Rodeheffer RJ. Burden of systolic and diastolic ventricular dysfunction in the community: appreciating the scope of the heart failure epidemic. JAMA. 2003;289(2):194-202

52. Wachtell K, Smith G, Gerdts E, et al. Left ventricular filling patterns in patients with systemic hypertension and left ventricular hypertrophy (the LIFE study). Losartan Intervention for Endpoint. Am. J. Cardiology. 2000;85(4):466-72.

53. Zile MR, Brutsaert DL. New concepts in diastolic dysfunction and diastolic heart failure: part I: diagnosis, prognosis, and measurements of diastolic function. Circulation. 2002;105(11):1387-93.

54. Smith VE, White WB, Meeran MK, Karimeddini MK. Improved left ventricular filling accompanies reduced left ventricular mass during therapy of essential hypertension. J Am Coll Cardiol. 1986;8(6):1449-54.

55. Nishimura RA, Tajik AJ. Evaluation of diastolic filling of left ventricle in health and disease: Doppler echocardiography is the clinician's Rosetta stone. J Am Coll Cardiol. 1997;30(1):8-18.

56. Schillaci G, Pasqualini $L$, Verdecchia $P$, et al. Prognostic significance of left ventricular diastolic dysfunction in essential hypertension. J Am Coll Cardiol. 2002:39(12):2005-11.

57. Ishida Y, Meisner JS, Tsujioka K, et al. Left ventricular filling dynamics: influence of left ventricular relaxation and left atrial pressure. Circulation. 1986;74(1):187-96.

58. Choong CY, Herrmann HC, Weyman AE, Fifer MA. Preload dependence of Doppler-derived indexes of left ventricular diastolic function in humans. J Am Coll Cardiol. 1987;10(4):800-8

59. Waggoner AD, Bierig SM. Tissue Doppler imaging: a useful echocardiographic method for the cardiac sonographer to assess systolic and diastolic ventricular function. J Am Soc Echocardiogr. 2001;14(12):1143-52.

60. Hurlburt HM, Aurigemma GP, Hill JC, et al. Direct ultrasound measurement of longitudinal, circumferential, and radial strain using 2-dimensional strain imaging in normal adults. Echocardiography. 2007;24(7):723-31.

61. Narayanan A, Aurigemma GP, Chinali M, Hill JC, Meyer TE, Tighe DA. Cardiac mechanics in mild hypertensive heart disease: a speckle-strain imaging study. Circ Cardiovasc Imaging. 2009;2(5):382-90.

62. Rathi VK, Doyle M, Yamrozik J, et al. Routine evaluation of left ventricular diastolic function by cardiovascular magnetic resonance: a practical approach. J Cardiovasc Magn Reson. 2008;10:36.

63. Rathi VK, Biederman RW. Expanding role of cardiovascular magnetic resonance in left and right ventricular diastolic function. Heart Fail Clin. 2009;5(3):421-35.

64. Rossi A, Temporelli PL, Quintana M, Dini FL, Ghio S, Hillis GS, Klein AL, Marsan NA, Prior DL, Yu CM, Poppe KK, Doughty RN, Whalley GA. MeRGE heart failure collaborators. Independent relationship of left atrial size and mortality in patients with heart failure: an individual patient meta-analysis of longitudinal data (MeRGE heart failure). Eur J Heart Fail. 2009;11:929-36.

65. Bangalore S, Yao SS, Chaudhry FA. Role of left atrial size in risk stratification and prognosis of patients undergoing stress echocardiography. J Am Coll Cardiol. 2007:50:1254-62.

66. Therkelsen SK, Groenning BA, Svendsen JH, Jensen GB. Atrial and ventricular volume and function in persistent and permanent atrial fibrillation, a magnetic resonance imaging study. J Cardiovasc Magn Reson. 2005;7:465-73. 
67. Raman SV. The hypertensive heart. An integrated understanding informed by imaging. J. Am.Coll. Cardiology. 2010;55(2):91-6.

68. Maceira AM, Cosín-Sales J, Roughton M, Prasad SK, Pennell DJ. Reference left atrial dimensions and volumes by steady state free precession cardiovascular magnetic resonance. J Cardiovasc Magn Reson. 2010;12:65.

69. Maron MS. Clinical utility of cardiovascular magnetic resonance in hypertrophic Cardiomyopathy. J Cardiovasc Magn Reson. 2012;14(1):13.

70. Petersen SE, Selvanayagam JB, Francis JM, Myerson SG, Wiesmann F, Robson MD, Ostman-Smith I, Casadei B, Watkins H, Neubauer S. Differentiation of athlete's heart from pathological forms of cardiac hypertrophy by means of geometric indices derived from cardiovascular magnetic resonance. J Cardiovasc Magn Reson. 2005;7:551-8.

71. Rudolph A, Abdel-Aty H, Bohl S, et al. Noninvasive detection of fibrosis applying contrast enhanced cardiac magnetic resonance in different forms of left ventricular hypertrophy relation to remodelling. J Am Coll Cardiol. 2009;53:284-91.

72. Moreo A, Ambrosio G, De Chiara B, et al. Influence of myocardial fibrosis on left ventricular diastolic function: noninvasive assessment by cardiac magnetic resonance and echo. Circ Cardiovasc Imaging. 2009;2(6):437-43.

73. Brilla CG, Funck RC, Rupp H. Lisinopril-mediated regression of myocardial fibrosis in patients with hypertensive heart disease. Circulation. 2000;102:1388-93.

74. Marcus ML, Koyanagi S, Harrison DG, Doty DB, Hiratzka LF, Eastham CL. Abnormalities in the coronary circulation that occur as a consequence of cardiac hypertrophy. Am J Med. 1983;75(3A):62-6.

75. Chan RH, Maron BJ, Olivotto I, Pencina MJ, Assenza GE, Haas T, Lesser JR, Gruner C, Crean AM, Rakowski H, Udelson JE, Rowin E, Lombardi M, Cecchi F, Tomberli B, Spirito P, Formisano F, Biagini E, Rapezzi C, De Cecco CN, Autore C, Cook EF, Hong SN, Gibson CM, Manning WJ, Appelbaum E, Maron MS. Prognostic value of quantitative contrast-enhanced cardiovascular magnetic resonance for the evaluation of sudden death risk in patients with hypertrophic cardiomyopathy. Circulation. 2014;130(6):484-95.

76. Kawaji K, Codella NC, Prince MR, Chu CW, Shakoor A, LaBounty TM, Min JK, Swaminathan RV, Devereux RB, Wang Y, Weinsaft JW. Automated segmentation of routine clinical cardiac magnetic resonance imaging for assessment of left ventricular diastolic dysfunction. Circ Cardiovasc Imaging. 2009;2:476-84.

77. Hinojar R, Varma N, Child N, Goodman B, Jabbour A, Yu CY, Gebker R, Doltra A, Kelle S, Khan S, Rogers T, Arroyo Ucar E, Cummins C, Carr-White G, Nagel E, Puntmann VO. T1 mapping in discrimination of hypertrophic phenotypes: hypertensive heart disease and hypertrophic Cardiomyopathy: findings from the international T1 multicenter cardiovascular magnetic resonance study. Circ Cardiovasc Imaging. 2015:8(12)

78. López B, González A, Querejeta R, Zubillaga E, Larman M, Díez J. Galectin-3 and histological, molecular and biochemical aspects of myocardial fibrosis in heart failure of hypertensive origin. Eur J Heart Fail. 2015;17(4):385-92.

79. Tandon A, Villa CR, Horn KN et al. J Am Heart Assoc. 2015;4(4).

80. Treibel TA, Zemrak F, Sado DM, Banypersad SM, White SK, Maestrini V, Barison A, Patel V, Herrey AS, Davies C, Caulfield MJ, Petersen SE, Moon JC. Extracellular volume quantification in isolated hypertension - changes at the detectable limits? J Cardiovasc Magn Reson. 2015;17:74

81. Hinojar R, Varma N, Child N, Goodman B, Jabbour A, Yu CY, Gebker R, Doltra A, Kelle S, Khan S, Rogers T, Arroyo Ucar E, Cummins C, Carr-White G, Nagel E, Puntmann VO. T1 mapping in discrimination of hypertrophic phenotypes: hypertensive heart disease and hypertrophic Cardiomyopathy: findings from the international T1 multicenter cardiovascular magnetic resonance study. Circ Cardiovasc Imaging. 2015;8(12):e003285.

82. López B, González A, Ravassa S, Beaumont J, Moreno MU, San José G, Querejeta R, Díez J. Circulating biomarkers of myocardial fibrosis: the need for a reappraisal. J Am Coll Cardiol. 2015;65(22):2449-56.

83. Lepojärvi ES, Piira OP, Pääkkö E, Lammentausta E, Risteli J, Miettinen JA, Perkiömäki JS, Huikuri HV, Junttila MJ. Serum PINP, PIIINP, galectin-3, and ST2 as surrogates of myocardial fibrosis and echocardiographic left venticular diastolic filling properties. Front Physiol. 2015;6:200.

84. Harvey A, Montezano AC, Lopez RA et al. Can J Cardiol. 2016;32(5):659-68.

85. Tsujita K, Yamanaga K, Komura N, Sakamoto K, Miyazaki T, Ishii M, Tabata N, Akasaka T, Sueta D, Arima Y, Kojima S, Yamamoto E, Yamamuro M, Tanaka T, Izumiya Y, Tayama S, Nakamura S, Kaikita K, Hokimoto S, Ogawa H. Impact of left ventricular hypertrophy on impaired coronary microvascular dysfunction. Int J Cardiol. 2015;187:411-3.

86. Petersen SS, Pedersen LR, Pareek M, Nielsen ML, Diederichsen SZ, Leósdóttir M, Nilsson PM, Diederichsen AC, Olsen MH. Factors associated with diagnostic discrepancy for left ventricular hypertrophy between electrocardiography and echocardiography. Blood Press. 2016;23:1-10.
87. Oseni AO, Qureshi WT, Almahmoud MF, Bertoni AG, Bluemke DA, Hundley WG, Lima JA, Herrington DM, Soliman EZ. Left ventricular hypertrophy by ECG versus cardiac MRI as a predictor for heart failure. Heart. 2017;103(1):49-54.

88. Levy D, Labib SB, Anderson KM, Christiansen JC, Kannel WB, Castelli WP. Determinants of sensitivity and specificity of electrocardiographic criteria for left ventricular hypertrophy. Circulation. 1990;81(3):815-20.

89. Kjaer A, Meyer C, Wachtell K, Olsen MH, Ibsen H, Opie L, Holm S, Hesse B. Positron emission tomographic evaluation of regulation of myocardial perfusion in physiological (elite athletes) and pathological (systemic hypertension) left ventricular hypertrophy. Am J Cardiol. 2005 15;96(12):1692-8.

90. Poe ND, Eber LM, Norman AS, Selin CE, Terao EN. Myocardial images in nonacute coronary and non coronary heart diseases. J Nucl Med. 1977;18(1):18-23.

91. Hoey ETD, Pakala V, Teoh JK, Simpson $\mathrm{H}$. The role of imaging in hypertensive heart disease. Int J Angiol. 2014;23(2):85-92.

92. Picano E, Palinkas A, Amyot R. Diagnosis of myocardial ischemia in hypertensive patients. J Hypertens. 2001;19(7):1177-83.

93. Bernhardt $P$, Levenson B, Albrecht A, Engels T, Strohm O. Detection of cardiac small vessel disease by adenosine-stress magnetic resonance. Int J Cardiol. 2007;121(3):261-6

94. Vogel-Claussen J, Skrok J, Dombroski D, Shea SM, Shapiro EP, Bohlman M, Lorenz CH, Lima JA, Bluemke DA. Comprehensive adenosine stress perfusion MRI defines the etiology of chest pain in the emergency room: comparison with nuclear stress test. J Magn Reson Imaging. 2009;30:753-62.

95. Ahn JH, Kim SM, Park SJ, Jeong DS, Woo MA, Jung SH, Lee SC, Park SW Choe YH, Park PW, Oh JK. Coronary Microvascular dysfunction as a mechanism of angina in severe AS: prospective adenosine-stress CMR study. J Am Coll Cardiol. 2016;67(12):1412-22.

96. Yilmaz A, Athanasiadis A, Mahrholdt H, Voehringer M, Ong P, Hill S, Kispert EM, Seebo M, Sechtem U. Diagnostic value of perfusion cardiovascular magnetic resonance in patients with angina pectoris but normal coronary angiograms assessed by intracoronary acetylcholine testing. Heart. 2010;96:372-9.

97. Nitenberg A, Pham I, Antony I, Valensi P, Attali JR, Chemla D. Cardiovascular outcome of patients with abnormal coronary vasomotion and normal coronary arteriography is worse in type 2 diabetes mellitus than in arterial hypertension: a 10 year follow-up study. Atherosclerosis. 2005;183:113-20.

98. Nadruz W, Shah AM, Solomon SD. Med Clin North Am. 2017;101(1):7-17.

99. Issa O, Peguero JP, Podesta C et al. J Cardiovasc Echogr. 2017;27(1):1-6.

\section{Submit your next manuscript to BioMed Central and we will help you at every step:}

- We accept pre-submission inquiries

- Our selector tool helps you to find the most relevant journal

- We provide round the clock customer support

- Convenient online submission

- Thorough peer review

- Inclusion in PubMed and all major indexing services

- Maximum visibility for your research

Submit your manuscript at www biomedcentral com/submit
C Biomed Central 